\title{
Impacts of energy saving strategies (ESSs) on rail services and related effects on travel demand
}

\author{
G. Corapi ${ }^{1}$, V. de Martinis ${ }^{1}$, A. Placido ${ }^{1}$ \& G. de Luca ${ }^{2}$ \\ ${ }^{1}$ Department of Civil, Architectural and Environmental Engineering, \\ Federico II University of Naples, Italy \\ ${ }^{2}$ Department of Engineering, University of Sannio (Benevento), Italy
}

\begin{abstract}
In railway systems, the evaluation of specific operating conditions and their impact on travel demand plays a key role both in planning and managing rail services. In this paper, we focus on the implementation of some energy saving strategies (ESSs) through the definition of energy-efficient speed profiles and estimate their effects on travel demand. In particular, speed profiles for ESSs need extra time for their implementation and hence entail a reduction in line performance. The definition of optimal speed profiles requires the use of optimisation procedures which can be formulated by considering motion parameters as control variables and energy consumption as the performance to be optimised (minimised), with respect to the available time. The proposed methodology is applied in the case of a real metro line, showing differences in user generalised costs, in order to provide additional information for rail operators which may allow evaluation of the best strategies to be adopted.

Keywords: energy saving strategies, user generalised costs, rail passenger systems, public transport management.
\end{abstract}

\section{Introduction}

In railway systems, the reduction in energy consumption is becoming a fundamental aspect to take into account in planning and managing rail services. Energy saving strategies (ESSs) consist in reducing energy consumption by modifying (i.e. optimising) train speed profile parameters (such as cruising speed, acceleration, deceleration and the coasting phases [1]), and improving 
driving behaviour through training and adopting Driving Assistance Systems (DASs) [2]. These procedures differ from those which consider energy recovery, i.e. through the use of regenerative braking systems and energy storage equipment and/or the optimisation of train timetables to maximise the percentage of energy recovered that can be used by other trains [3] or better fit the needs and availabilities of electric power systems [4].

The current level of automation in rail system controls allows both reliability and safety in train operations with low headways and high energy efficiency [5, 6]. Moreover, interesting results have been obtained by generating a data warehouse containing predefined speed profiles for selecting the one which best fits strategy requirements [7]. Other significant results on specific rail systems were reported, for instance, in the case of freight train operations [8], planning mass rapid transit systems [9] and moving block signalling systems [10].

Given the role of speed profiles for optimal energy-efficient driving implementation, the single train speed profile definition is particularly important for rail system modelling [11]. One of the most widely studied ESS approaches entails the formulation of an optimal control problem [2] which has been specified for different control cases (discrete and continuous) and operation conditions $[12,13]$, although some limitations related to the strong non-linearity and instability have to be evaluated [14].

By applying a dynamic programming approach, the optimisation problem can be decomposed into several simpler sub-problems and solved with recursive methods. Some major results have been shown through the definition of a multistage decision process [15-17]. As regards the train/driver interaction, [18] proposed an energy-optimal train control which was applied to driver advisory systems, based on a bi-level algorithm which led to the energy-optimal regime sequence with the minimal number of regime changes, in order to be easily followed by the driver.

This paper focuses on the implementation of some ESSs and estimation of related effects on travel demand. Recently, some authors [19-22] have investigated the interaction between rail intervention strategies in the case of system failures and travel demand in terms of travel and waiting times. The effects of public transport quality on user choices have been investigated by [23] and [24], and the use of macroscopic simulation models for optimising public transport performance (such as service frequencies) have been proposed by [25] and [26]. Indeed, recent trends have focused on the use of public transport as a tool for reducing negative effects on the environment and on urban life quality (see, for instance, [27-30]). Finally, some have proposed the use of microscopic simulation models to determine some optimal driving strategies in the case of rail systems $[31,32]$.

This paper is organised as follows: Section 2 proposes a general framework for analysing the effects of ESSs in terms of energy consumption and quality of services for passengers; Section 3 tests the proposed methodology in the case of a real-dimension network; finally, conclusions are drawn and research prospects outlined in Section 4. 


\section{General methodology for implementing energy saving strategies (ESSs)}

The implementation of energy-efficient driving strategies is often seen as one of the options for utilising residual capacity. Indeed, extra time availability on a given line service can be used either to optimise capacity or for energy saving. Moreover, together with the use of this extra time, the planned quality of service perceived by the users has to be ensured. The extra times involved in these optimisation procedures are usually the recovery times, classified in time for small delay recovery (running time reserve, dwell time reserve) and time for avoiding delay propagation (buffer time). These times are computed during timetable planning, adding to the minimum times required for services (i.e. minimum running time, minimum dwell time, minimum headway) a percentage of those or a convenient value that satisfies service quality considering a given randomness of the events; for example, running time reserve is often computed as $3-7 \%$ of the minimum running time. The use of this extra time for energy saving purposes should be supported by proof of timetable stability, and more generally, by respect of the level of service [33]. Therefore, suitably calibrated simulation tools should be able to support estimation of service quality.

\subsection{Energy saving strategies (ESSs)}

In the following, we refer to speed profiles as the operative aspects of an adopted ESS. Following the formulations of supply design models (see [34] for a complete definition), a suitable speed profile for energy saving can be designed for an initial optimisation phase. Then a feasible operating scenario is defined by a simulation phase where the operating performance of the whole system is estimated and evaluated. Therefore, evaluation of service quality can give important information about the feasibility of the proposed scenario, i.e. the adopted ESS.

The optimisation phase can be formulated as an optimisation problem [32]:

$$
\left[a^{*}, V_{\max }^{*}, d^{*}, T_{i C}^{*}, T_{f C}^{*}\right]=\arg \min _{a, V_{\max }, d T_{i C}, T_{f C}} E\left(a, V_{\max }, d T_{i C}, T_{f C}\right)
$$

subject to:

$$
\begin{aligned}
& J * 1 s<a \leq a_{\max } \\
& V_{\min }<V_{\max } \leq V_{\text {allow }} \\
& J * 1 s<d \leq d_{\max }
\end{aligned}
$$

where $a$ is the target acceleration ( $a^{*}$ is its optimal value); $V_{\max }$ is the target speed ( $V_{\max }^{*}$ is its optimal value); $d$ is the target deceleration $\left(d^{*}\right.$ is its optimal value); $T_{i C}$ is the starting time of coasting phase $\left(T^{*}{ }_{i C}\right.$ is its optimal value); $T_{f C}$ is the ending time of the coasting phase $\left(T_{f C}^{*}\right.$ is its optimal value). The function to be minimised is the energy consumption model $E($.$) , whose value is a function of$ the adopted speed profile. Constraints are given by $J \cdot 1 s$, which is the 
acceleration at 1 second, obtained by multiplying the variation of acceleration (also known as jerk) value by 1 second; $a_{\max }$ and $d_{\max }$ are respectively maximum acceleration and maximum deceleration, taking passenger comfort into account.

Other additional constraints can be considered for specific operating conditions, such as:

$$
\begin{gathered}
T_{i C}<T_{f C} \\
T_{f C}+T_{\text {dec }}\left(V\left(T_{f C}\right)\right) \leq T_{\text {max }} \\
S_{\text {acc }}+S_{\text {cruise }}+S_{\text {coas }}+S_{\text {dec }}=\text { Dist }
\end{gathered}
$$

where $T_{d e c}$ is the time needed to decelerate from a certain speed; $T_{\max }$ is the maximum travel time compatible with the timetable (e.g. the sum of the minimum running time and the running time reserve); $S_{a c c}$ is the space covered during acceleration; $S_{\text {cruise }}$ is the space covered during cruising; $S_{\text {coast }}$ is the space covered during coasting; $S_{d e c}$ is the space covered during deceleration; Dist is the total distance to be covered. Equation (5) lets the procedure respect the simple constraint that the end of the coasting regime cannot precede the start; equation (6) is specific for those strategies which introduce the coasting phase only before final braking; equation (7) ensures the respect of the distance to cover (e.g. distance station-to-station).

By applying the finite difference approach to the general equation of the motion, the energy consumption $E$ model can be expressed as:

$$
E=\sum_{i=1 \ldots T} V_{i} \cdot F_{i}\left(V_{i}, t_{i}\right)
$$

with

$$
F_{i}\left(V_{i}, t_{i}\right)=M \cdot f_{p} \cdot \frac{\left(V_{i+1}-V_{i}\right)}{\left(t_{i+1}-t_{i}\right)}+R\left(V_{i}, S_{i}\right)
$$

where Equation (9) is constrained by adherence conditions on track and traction unit performance.

Hence, the operating scenario given by the optimisation phase can be implemented in a simulation environment for estimating performance of the whole system.

\subsection{Travel demand estimation and interaction}

In order to understand the effects of ESS on customers, it is necessary to assign the travel demand to the rail network so as to evaluate the generalised cost perceived by the users. As shown by [20] and [21], this process can be analysed by means of two models, a pre-platform model and an on-platform model. The former describes user behaviour conditioned by the performance of the transportation system and evaluates passenger flows that use the rail service. This model is generally implemented by four sub-models: an emission model, a distribution model, a mode choice model and a path choice model (see [34] for more details). The latter estimates the interaction between passengers and the rail service considering the capacity constraints of rail convoys. In particular, for 
each train the model checks whether there is enough residual capacity to let all the waiting passengers, or just a portion of them, get on the first approaching rail convoy. If this condition is not satisfied, the other passengers have to wait on the platform for the following train, thereby increasing their waiting time. Obviously, according to an FIFO (First In - First Out) approach, these passengers will have priority in boarding the following trains. Therefore, the onplatform model provides the actual boarding passengers, allowing travel and waiting times to be determined for each user. Thus it is possible to determine the generalised cost perceived during the service as follows:

$$
Z=\beta_{\text {waiting }} \cdot \sum_{s} \sum_{p} \sum_{r} t w_{s, p}^{r} \cdot f w_{s, p}^{r}+\beta_{\text {on-board }} \cdot \sum_{l} \sum_{r} t b_{l}^{r} \cdot f b_{l}^{r}
$$

where $\mathrm{Z}$ is the total generalised cost of the simulated scenario; $\beta_{\text {waiting }}$ is the weight of the waiting time for the user that is usually set at 2.5 (see [34] for more details); $t w_{s, p}^{r}$ is the average user waiting time at station $s$ on platform $p$ between run $(r-1)$ and run $r ; f w_{s, p}^{r}$ is the number of passengers waiting at station $s$ on platform $p$ between run $(r-1)$ and run $r ; \beta_{\text {on-board }}$ is the weight of the on-board time for the user that is usually set at $1 ; t b_{l}^{r}$ is the time spent by the users on board run $r$ for travelling on link $l ; f b_{l}^{r}$ is the number of passengers who travel on board run $r$ along link $l$.

\subsection{Proposed framework for impact evaluation}

The proposed framework (see Figure 1) consists of a database of infrastructure and signalling system characteristics, timetable plans and rolling stock features (see [31] for details).

As previously mentioned, in addition to this static information, data on extra time availability have to be retrieved either through real data on arrivals and departures and on speed profiles or via simulation. The optimisation phase defines station to station speed profiles according to eqn. (1) and the related constraints. Firstly, through a genetic algorithm, acceleration, speed and deceleration parameters are defined; then, in a second step, the switching points of the coasting phase are computed. Once the speed profile is known, it is possible to estimate, through the general equation of motion, the corresponding energy consumption to minimise. The output of the optimisation phase defines a new operating scenario to be simulated. Simulation outputs, such as delays, conflicts and running times for a given time reference are then evaluated in terms of generalised costs perceived by the users. After the evaluation procedure, if the proposed scenario is not acceptable, another scenario can be defined, taking into account a reduction in the considered values of running time reserve.

\section{Applications in the case of a real scale network}

The above described framework was tested with real data of the urban metro line MetroNapoli Linea 1, in the city of Naples (Italy). This railway line serves a total of 15 stations on a route of about $14 \mathrm{kms}$ (Figure 2); services between Piscinola 
and Dante are supported by a double track, while a provisional shuttle serves the newest part between Dante and Università, using a single track and a single train, looking forward to the conclusion of the second track. Each train comprises three electric multiple units with a total capacity of 1251 passengers/train. The timetable in terms of headways is:

- 12 minutes (i.e. 5 trains/hour) between 6.00 a.m. and 7.00 a.m.;

- 7 minutes (i.e. 8.6 trains/hour) between 7.00 a.m. and 9.00 a.m.;

- 10 minutes (i.e. 6 trains/hour) between 9.00 a.m. and 2.00 p.m.

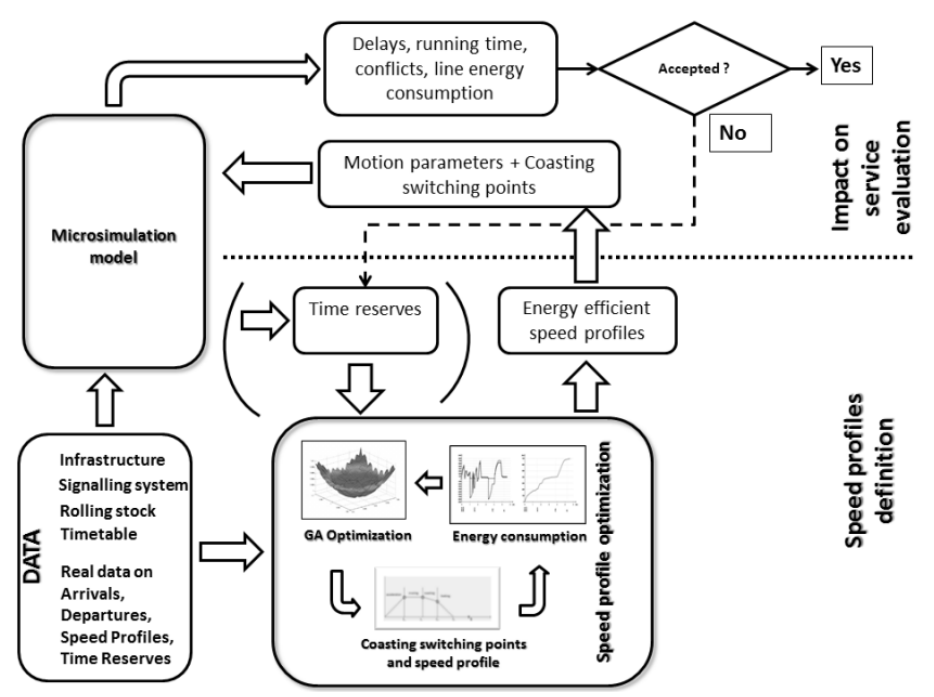

Figure 1: Functional scheme of the proposed framework.

This line is being investigated by several ongoing research projects and, for our purposes, an already calibrated simulation model was used for two different ESS implementations:

- First Strategy: in this case only Running Time Reserves are computed as the difference between Minimum Running Time and scheduled running time;

- Second Strategy: in this case, the time available for implementing ESS also considers the difference between buffer times, computed at each section, and the minimum buffer time computed at the critical section. 


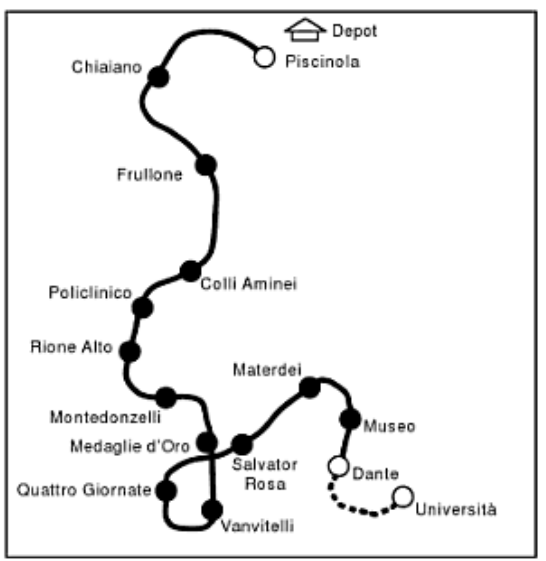

Figure 2: The MetroNapoli Linea 1 layout.

Table 1: Results of first strategy implementation.

\begin{tabular}{|c|c|c|c|c|}
\hline & \multirow{2}{*}{\multicolumn{2}{|c|}{ Dante-Piscinola }} & & \\
\hline & & & \multicolumn{2}{|c|}{ Piscinola-Dante } \\
\hline & $\begin{array}{l}\text { Variation in } \\
\text { train } \\
\text { running time }\end{array}$ & $\begin{array}{c}\text { Variation in } \\
\text { energy } \\
\text { consumption }\end{array}$ & $\begin{array}{c}\text { Variation in } \\
\text { train } \\
\text { running time }\end{array}$ & $\begin{array}{c}\text { Variation in } \\
\text { energy } \\
\text { consumption }\end{array}$ \\
\hline Dante-Museo & $0.00 \%$ & $0.00 \%$ & $0.00 \%$ & $0.00 \%$ \\
\hline Museo-Materdei & $0.00 \%$ & $0.00 \%$ & $0.00 \%$ & $0.00 \%$ \\
\hline Materdei-Salvator Rosa & $9.84 \%$ & $-17.97 \%$ & $9.84 \%$ & $-24.26 \%$ \\
\hline Salvator Rosa-Cilea & $6.45 \%$ & $-19.82 \%$ & $0.00 \%$ & $0.00 \%$ \\
\hline Cilea-Vanvitelli & $0.00 \%$ & $0.00 \%$ & $0.00 \%$ & $0.00 \%$ \\
\hline $\begin{array}{c}\text { Vanvitelli-Medaglie } \\
\text { d'Oro }\end{array}$ & $8.70 \%$ & $-5.78 \%$ & $11.11 \%$ & $-12.52 \%$ \\
\hline $\begin{array}{l}\text { Medaglie d'Oro-- } \\
\text { Montedonzelli }\end{array}$ & $0.00 \%$ & $0.00 \%$ & $6.74 \%$ & $-15.18 \%$ \\
\hline $\begin{array}{c}\text { Montedonzelli-Rione } \\
\text { Alto }\end{array}$ & $2.60 \%$ & $-2.59 \%$ & $0.00 \%$ & $0.00 \%$ \\
\hline Rione Alto-Policlinico & $15.09 \%$ & $-9.00 \%$ & $15.09 \%$ & $29.73 \%$ \\
\hline Policlinico-Colli Aminei & $8.33 \%$ & $-2.42 \%$ & $12.86 \%$ & $-14.93 \%$ \\
\hline Colli Aminei-Frullone & $0.00 \%$ & $0.00 \%$ & $0.00 \%$ & $0.00 \%$ \\
\hline Frullone-Chiaiano & $0.00 \%$ & $0.00 \%$ & $0.00 \%$ & $0.00 \%$ \\
\hline Chiaiano-Piscinola & $0.00 \%$ & $0.00 \%$ & $0.00 \%$ & $0.00 \%$ \\
\hline $\begin{array}{c}\text { Variation in energy } \\
\text { consumption }\end{array}$ & $-3.38 \%$ & & $-4.20 \%$ & \\
\hline $\begin{array}{l}\text { Variation in train } \\
\text { running time }\end{array}$ & $3.07 \%$ & & $3.40 \%$ & \\
\hline
\end{tabular}

For both scenarios, the increase in running time and the corresponding decrease in energy were calculated for each section. The results of the first and second strategies are reported respectively in Tables 1 and 2. The first strategy 
was applied differently in the two directions: six station-to-station sections for the direction from Dante to Piscinola and five sections in the opposite direction. In our case, data on real arrival and departure times, and real speed profiles were missing or incomplete, and a single simulation with time optimal strategy was run in order to estimate the missing data and the differences relative to the scheduled timetable. Taking into consideration the randomness of the events from previous studies [21], a restrictive rate of $20 \%$ of the estimated time reserves was used for ESS. Moreover, the selected sections are those for which the time for ESS implementation was at least 10s per section.

Table 2: Results of second strategy implementation.

\begin{tabular}{ccccc}
\cline { 2 - 5 } & \multicolumn{2}{c}{ Dante-Piscinola } & \multicolumn{2}{c}{ Piscinola-Dante } \\
\cline { 2 - 5 } & $\begin{array}{c}\text { Variation in } \\
\text { train } \\
\text { running time }\end{array}$ & $\begin{array}{c}\text { Variation in } \\
\text { energy } \\
\text { consumption }\end{array}$ & $\begin{array}{c}\text { Variation in } \\
\text { train } \\
\text { running time }\end{array}$ & $\begin{array}{c}\text { Variation in } \\
\text { energy } \\
\text { consumption }\end{array}$ \\
\hline Dante-Museo & $8.00 \%$ & $-17.92 \%$ & $8.70 \%$ & $-21.20 \%$ \\
Museo-Materdei & $6.25 \%$ & $-22.04 \%$ & $8.91 \%$ & $-20.11 \%$ \\
Materdei-Salvator Rosa & $9.84 \%$ & $-17.97 \%$ & $9.84 \%$ & $-24.26 \%$ \\
Salvator Rosa-Cilea & $6.45 \%$ & $-19.82 \%$ & $7.45 \%$ & $-19.65 \%$ \\
Cilea-Vanvitelli & $4.12 \%$ & $-22.38 \%$ & $4.55 \%$ & $21.09 \%$ \\
Vanvitelli-Medaglie & $8.70 \%$ & $-5.78 \%$ & $11.11 \%$ & $-12.52 \%$ \\
$\begin{array}{c}\text { d'Oro } \\
\text { Medaglie d'Oro- }\end{array}$ & $8.24 \%$ & $-25.87 \%$ & $6.74 \%$ & $-15.18 \%$ \\
$\begin{array}{c}\text { Montedonzelli } \\
\text { Montedonzelli-Rione }\end{array}$ & $9.09 \%$ & $-16.99 \%$ & $13.33 \%$ & $-11.41 \%$ \\
$\begin{array}{c}\text { Alto } \\
\text { Rione Alto-Policlinico }\end{array}$ & $0.00 \%$ & $0.00 \%$ & $0.00 \%$ & $0.00 \%$ \\
Policlinico-Colli Aminei & $8.33 \%$ & $-2.42 \%$ & $12.86 \%$ & $-14.93 \%$ \\
Colli Aminei-Frullone & $4.04 \%$ & $-18.29 \%$ & $7.53 \%$ & $-17.41 \%$ \\
$\begin{array}{c}\text { Frullone-Chiaiano } \\
\text { Chiaiano-Piscinola }\end{array}$ & $9.00 \%$ & $-17.93 \%$ & $8.51 \%$ & $-10.29 \%$ \\
\hline $\begin{array}{c}\text { Variation in energy } \\
\text { consumption }\end{array}$ & $6.15 \%$ & $-6.49 \%$ & $6.48 \%$ & $-15.11 \%$ \\
\hline $\begin{array}{c}\text { Variation in train } \\
\text { running time }\end{array}$ & $\mathbf{- 1 5 . 0 4 \%}$ & & $\mathbf{- 1 5 . 5 0 \%}$ & \\
\hline & $\mathbf{6 . 7 8 \%}$ & & $\mathbf{8 . 0 8 \%}$ & \\
\hline
\end{tabular}

In Figure 3, an example of the sections considered for the first strategy implementation is reported. The runs Colli Aminei-Policlinico and PoliclinicoRione Alto were considered for implementation, while Frullone-Colli Aminei were simulated only with a Time Optimal speed profile. The second ESS was applied in all sections except for the critical section Policlinico-Rione Alto. With the increase in extra time available for ESS, the possibility of lower energy consumption increases. In Figure 4 an example of second strategy implementation is shown, with the minimum buffer time being considered as the time available for implementing energy saving strategies. 


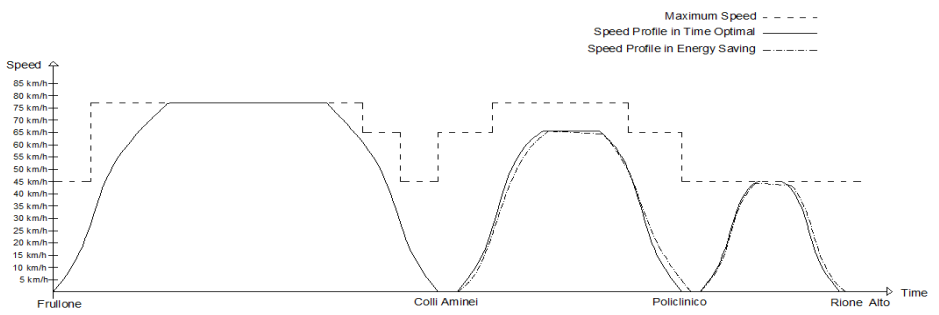

Figure 3: Speed profile of second strategy implementation.

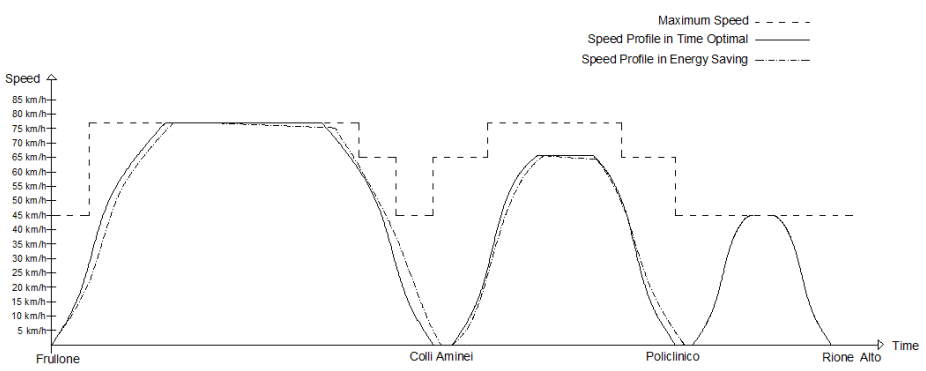

Figure 4: Speed profile of second strategy implementation.

Table 3: Energy reduction benefit in a generic working day.

\begin{tabular}{|c|c|c|c|c|c|c|c|c|c|}
\hline \multirow{2}{*}{\multicolumn{2}{|c|}{ Strategy }} & \multicolumn{2}{|c|}{$\begin{array}{c}\text { Energy } \\
\text { consumption } \\
\text { (Kwh/train) }\end{array}$} & \multicolumn{2}{|c|}{$\begin{array}{c}\text { Energy } \\
\text { cost } \\
(€ / \text { Kwh*train) } \\
\end{array}$} & \multirow[t]{2}{*}{ Train/day } & \multicolumn{2}{|c|}{$\begin{array}{c}\text { Energy } \\
\text { cost } \\
(€ / \text { day })\end{array}$} & \multirow[t]{2}{*}{$\begin{array}{l}\text { Saving } \\
\text { (€/day) }\end{array}$} \\
\hline & & TO & ES & TO & ES & & TO & ES & \\
\hline \multirow{2}{*}{1} & $\begin{array}{l}\text { Dante } \rightarrow \\
\text { Piscinola }\end{array}$ & 138.8 & 134.1 & 48.58 & 46.94 & 113 & 5489.5 & 5303.9 & 185.55 \\
\hline & $\begin{array}{l}\text { Piscinola } \\
\rightarrow \text { Dante }\end{array}$ & 127.7 & 122.3 & 44.695 & 42.82 & 113 & 5050.5 & 4838.4 & 212.12 \\
\hline \multirow{2}{*}{2} & $\begin{array}{l}\text { Dante } \rightarrow \\
\text { Piscinola }\end{array}$ & 131.4 & 111.6 & 45.99 & 39.07 & 113 & 5196.8 & 4415.2 & 781.61 \\
\hline & $\begin{array}{l}\text { Piscinola } \\
\rightarrow \text { Dante }\end{array}$ & 125.2 & 105.8 & 43.82 & 37.03 & 113 & 4951.6 & 4184.1 & 767.51 \\
\hline
\end{tabular}

Table 4: Variation in generalised costs in a generic working day $(€ \times 1,000)$.

\begin{tabular}{ccccccc|ccc}
\hline \multicolumn{4}{c|}{ Time optimal } & \multicolumn{3}{c|}{ Energy saving } & \multicolumn{3}{c}{ Variation } \\
\hline & Fleet 1 & Fleet 2 & Fleet 3 & Fleet 1 & Fleet 2 & Fleet 3 & Fleet 1 & Fleet 2 & Fleet 3 \\
\hline 95th \% & 258.4 & 258.3 & 259.0 & 258.9 & 258.8 & 259.5 & $0.20 \%$ & $0.20 \%$ & $0.21 \%$ \\
\hline 85th \% & 222.9 & 222.9 & 223.2 & 223.3 & 223.3 & 223.7 & $0.20 \%$ & $0.20 \%$ & $0.22 \%$ \\
\hline 50 th \% & 172.1 & 172.1 & 172.1 & 172.4 & 172.4 & 172.4 & $0.19 \%$ & $0.19 \%$ & $0.19 \%$ \\
\hline
\end{tabular}


In order to highlight the speed profile differences, the speed distance diagram that results from the second strategy implementation is reported with respect to the same stations shown in Figure 3. Tables 3 and 4 show respectively the monetary effect of energy consumption reduction, assuming an energy price of $0.35 € / \mathrm{kWh}$, and the variation in generalised costs perceived by the users. All elaborations refer to a generic working day.

\section{Conclusions and research prospects}

This paper approached the problem of evaluating the impacts of energy-efficient driving strategies on users. It was shown that when different kinds of energy saving driving strategies are adopted, the specific increase in the generalised cost perceived by the user is not influential, i.e. the service quality is perceived as unvaried. In future research a monitoring phase will be implemented on a test rail line, allowing the results of the proposed framework to be improved by estimating the distributions of the real departures and arrivals and the related speed profile parameters and dwelling times.

\section{Acknowledgements}

This paper is partially supported under research projects PON - SFERE grant no. PON01_00595 and PON - DigITAL PATTERN grant no. PON01_01268.

\section{References}

[1] Sicre, C., Cucala, A.P., Fernàndez, A. \& Lukaszewicz P., Modeling and optimizing energy-efficient manual driving on high-speed lines. IEEJ Transaction on Electrical and Electronic Engineering, 7(6), pp. 633-640, 2012.

[2] Hansen, I.A. \& Pachl, J., Railway, timetable \& traffic: Analysis, modelling, simulation. Eurailpress: Hamburg, Germany, 2008.

[3] Malavasi, G., Palleschi, P. \& Ricci, S., Driving and operation strategies for traction-energy saving in mass rapid transit systems. Journal of Rail and Rapid Transit, 225(5), pp. 475-482, 2011.

[4] Iannuzzi, D. \& Tricoli, P., Metro trains equipped onboard with supercapacitors: a control technique for energy saving. Proc. of the International Symposium on Power Electronics, Electrical Drives, Automation and Motion (SPEEDAM), pp. 750-756, 2010.

[5] Liu, R. \& Golovicher, I.M., Energy-efficient operation of rail vehicles. Transportation Research Part A, 37(10), pp. 917-932, 2003.

[6] Domínguez, M., Fernández-Cardador, A., Cucala, A.P. \& Pecharromán, R.R., Energy savings in metropolitan railway substations through regenerative energy recovery and optimal design of ATO speed profiles. IEEE Transactions on Automation Science and Engineering, 9(3), pp. 496-504, 2012. 
[7] Miyatake, M. \& Ko, H., Optimization of train speed profile for minimum energy consumption. IEEJ Transactions on Electrical and Electronic Engineering, 5(3), pp. 263-269, 2010.

[8] Lukaszewicz, P., Energy saving driving methods for freight trains. Advances in Transport, 15, pp. 901-909, 2004.

[9] Ke, B.R. \& Chen, N., Signalling block layout and strategy of train operation for saving energy in mass rapid transit systems. IEE Proceedings in Electric Power Applications, 152(2), pp. 129-140, 2005.

[10] Gu, Q., Lu, X.-Y. \& Tang, T., Energy saving for automatic train control in moving block signalling system. Proc. of the 14th IEEE Conference on Intelligent Transportation Systems (ITSC), pp. 1305-1310, 2011.

[11] Bocharnikov, Y.V., Tobias, A.M. \& Roberts, C., Reduction of train and net energy consumption using genetic algorithms for trajectory optimization. IET Conference on Railway Traction Systems (RTS), pp. 1$5,2010$.

[12] Howlet, P., The optimal control of a train. Annals of Operations Research, 98(1-4), pp. 65-87, 2000.

[13] Khmelnitsky, E, On an optimal control problem of train operation. IEEE Transactions on Automatic Control, 45(7), pp. 1257-1266, 2000.

[14] Wang, Y., De Shutter, B., van den Boom, T.J.J. \& Ning B., Optimal trajectory planning for trains - A pseudospectral method and a mixed integer linear programming approach. Transportation Research Part C, 29, pp. 97-114, 2013.

[15] Albrecht, T. \& Oettich, S., A new integrated approach to dynamic schedule synchronization and energy saving train control. WIT Transaction on the Built Environment, 61, pp. 847-856, 2002.

[16] Franke, R., Terwiesch, P. \& Meyer, M., An algorithm for the optimal control of the driving of trains. Proc. of the 39th IEEE Conference on Decision and Control, pp. 2123-2128, 2003.

[17] Ko, H., Koseki, T. \& Miyatake, M., Application of dynamic programming to optimization of running profile of a train. WIT Transaction on the Built Environment, 74, pp. 103-112, 2004.

[18] Albrecht, T., Gassel, C., Binder, A. \& van Luipen, J., Dealing with operational constraints in energy efficient driving. IET Conference on Railway Traction Systems (RTS), pp. 1-7, 2010.

[19] Quaglietta, E., D’Acierno, L., Punzo, V., Nardone, R. \& Mazzocca, N., A simulation framework for supporting design and real-time decisional phases in railway systems. Proc. of the 14th IEEE Conference on Intelligent Transportation Systems (ITSC), pp. 846-851, 2011.

[20] D'Acierno, L., Gallo, M., Montella, B. \& Placido, A., Analysis of the interaction between travel demand and rail capacity constraints. WIT Transactions on the Built Environment, 128, pp. 197-207, 2012.

[21] D'Acierno, L., Gallo, M., Montella, B. \& Placido, A., The definition of a model framework for managing rail systems in the case of breakdowns. Proc. of the 16th IEEE Conference on Intelligent Transportation Systems (ITSC), pp. 1059-1064, 2013. 
[22] Ercolani, M., Placido, A., D'Acierno, L. and Montella, B., The use of microsimulation models for the planning and management of metro systems. WIT Transactions on the Built Environment, 135, 2014.

[23] Cascetta, E. \& Cartenì, A., A quality-based approach to public transportation planning: theory and a case study. International Journal of Sustainable Transportation, 8(1), pp. 84-106, 2014.

[24] Cascetta, E., Cartenì, A. \& Carbone, A., The quality in public transportation. The Campania regional metro system. Ingegneria Ferroviaria, 68(3), pp. 241-261, 2013.

[25] Gallo, M., D’Acierno, L. \& Montella, B., A multimodal approach to bus frequency design. WIT Transactions on the Built Environment, 116, pp. 193-204, 2011.

[26] Gallo, M., Montella, B. \& D'Acierno, L., The transit network design problem with elastic demand and internalisation of external costs: An application to rail frequency optimisation. Transportation Research Part C, 19(6), pp. 1276-1305, 2011.

[27] Gallo, M., A fuel surcharge policy for reducing road traffic greenhouse gas emissions. Transport Policy, 18(2), pp. 413-424, 2011.

[28] Gallo, M., D'Acierno, L. \& Montella, B., A multilayer model to simulate cruising for parking in urban areas. Transport Policy, 18(5), pp. 735-744, 2011.

[29] D’Acierno, L., Ciccarelli, R., Montella, B. \& Gallo, M., A multimodal multiuser approach for analysing pricing policies in urban contexts. Journal of Applied Sciences, 11(4), pp. 599-609, 2011.

[30] Biggiero, L., The impact of transport management on local activities system: The role of limited traffic zones. WIT Transactions on the Built Environment, 138, 2014.

[31] Corapi, G., Sanzari, D., De Martinis, V., D’Acierno, L. \& Montella, B., A simulation-based approach for evaluating train operating costs under different signalling systems. WIT Transactions on the Built Environment, 130, pp. 149-161, 2013.

[32] De Martinis, V., Gallo, M. \& D'Acierno, L., Estimating the benefits of energy-efficient train driving strategies: a model calibration with real data. WIT Transactions on the Built Environment, 130, pp. 201-211, 2013.

[33] Goverde, R. M. P., A delay propagation algorithm for large-scale railway traffic networks. Transportation Research Part C, 18, pp. 269-287, 2010.

[34] Cascetta E., Transportation system analysis: Models and applications, Springer: New York, 2009. 